\title{
Design impact and significance of non-stationarity of variance in extreme rainfall
}

\author{
M. Al Saji ${ }^{1}$, J. J. O'Sullivan ${ }^{1}$, and A. O'Connor ${ }^{2}$ \\ ${ }^{1}$ Earth Institute and School of Civil, Structural and Environmental Engineering, University College Dublin, \\ Dublin, Ireland \\ ${ }^{2}$ Department of Civil, Structural and Environmental Engineering, Trinity College Dublin, Dublin, Ireland \\ Correspondence to: M. Al Saji (mohammed.al-saji@ucdconnect.ie)
}

Received: 11 March 2015 - Accepted: 11 March 2015 - Published: 12 June 2015

\begin{abstract}
Stationarity in hydro-meteorological records is often investigated through an assessment of the mean value of the tested parameter. This is arguably insufficient for capturing fully the non-stationarity signal, and parameter variance is an equally important indicator. This study applied the Mann-Kendall linear and MannWhitney-Wilcoxon step change trend detection techniques to investigate the changes in the mean and variance of annual maximum daily rainfalls at eight stations in Dublin, Ireland, where long and high quality daily rainfall records were available. The eight stations are located in a geographically similar and spatially compact region $\left(<950 \mathrm{~km}^{2}\right)$ and their rainfalls were shown to be well correlated. Results indicate that while significant positive step changes were observed in mean annual maximum daily rainfalls (1961 and 1997) at only two of the eight stations, a significant and consistent shift in the variance was observed at all eight stations during the 1980's. This period saw a widely noted positive shift in the winter North Atlantic Oscillation that greatly influences rainfall patterns in Northern Europe.

Design estimates were obtained from a frequency analysis of annual maximum daily rainfalls (AM series) using the Generalised Extreme Value distribution, identified through application of the Modified Anderson Darling Goodness of Fit criterion. To evaluate the impact of the observed non-stationarity in variance on rainfall design estimates, two sets of depth-frequency relationships at each station for return periods from 5 to 100 -years were constructed. The first was constructed with bootstrapped confidence intervals based on the full AM series assuming stationarity and the second was based on a partial AM series commencing in the year that followed the observed shift in variance. Confidence intervals distinguish climate signals from natural variability. Increases in design daily rainfall estimates obtained from the depth-frequency relationship developed from the truncated AM series, as opposed to those using the full series, ranged from 5 to $16 \%$ for the 5 -year event and from 20 to $41 \%$ for the 100-year event. Results indicate that the observed trends exceed the envelopes of natural climate variability and suggest that the non-stationarity in variance is associated with a climate change signal. Results also illustrate the importance of considering trends in higher order moments (e.g. variance) of hydro-meteorological variables in assessing non-stationarity influences.
\end{abstract}

\section{Introduction}

Climate induced non-stationarity in hydro-meteorological variables has significant impacts on the engineering design of water systems. While complex, failure to correctly identify and account for non-stationarity influences can compromise the reliability of design estimates which are typically obtained from frequency analyses of historical time series of extreme events (Coles, 2001; Klein Tank et al., 2009). Such frequency analyses are commonly underpinned by the assumption of stationarity, i.e. observations are independent and identically distributed (Stedinger, 1993). Once this assumption is violated, errors in design estimates which impact on risk levels and/or economic costs are likely (Kundzewicz and Robson, 2000). 
Climate studies have suggested that extreme hydrometeorological data can exhibit significant trends, from either natural climate variability or from climate change (Burn and Hag Elnur, 2002; Dawadi and Ahmad, 2012; IPCC, 2012; Jung et al., 2011; Osborn and Hulme, 2000; Robson et al., 1998; Sen Roy and Balling, 2004; De Toffol et al., 2009). In Ireland, the precipitation pattern is highly influenced by the North Atlantic Oscillation (NAO) (Hurrell, 1995; Rodwell et al., 1999; Sheridan, 2001; Sweeney, 2014). The NAO reflects changes in the pressure gradient between Iceland and the Azores (Jones et al., 1997; Visbeck and Hurrell, 2001) and when this index is high (low pressure in Iceland and high in the Azores), enhanced westerly air currents are more vigorous, bringing heavy precipitation to northern and north-west Europe (Arnell, 1999). Since the beginning of the 1980's, the NAO has remained in a relatively extreme positive phase accounting for wetter-than-normal conditions in northern Europe and Scandinavia (Hurrell and Van Loon, 1997; Hurrell, 1995; López and Francés, 2013; Trigo et al., 2004). Positive shifts in annual rainfall totals accompanied by a change in the frequency of occurrence of extreme events in the mid and late 1970's have, in Ireland, been associated with a predominantly positive phase of the winter NAO index since 1980 (Chandler, 2002; Hoppe and Kiely, 1999; Leahy and Kiely, 2010).

Climatic trends, particularly in extremes, change the probability distribution function (pdf) in the form of a shift in location, a change in variance or a change in the shape of the distribution (Hannachi, 2006). These changes can be reflected in gradual monotonic changes and/or abrupt shifts in parameter values.

Changes in parameter variability (included in second order statistical testing) have traditionally received relatively little attention in scientific literature (Pegram, 2000). In this study, the non-stationarity in variance, in addition to the mean, of extreme daily rainfall (AM series) at eight stations with long historical records in Dublin is explored using the MannKendall (MK) linear and Mann-Whitney-Wilcoxon (MWW) step change trend detection techniques. The eight stations are located in a geographically similar and spatially compact region $\left(<950 \mathrm{~km}^{2}\right)$ and their rainfalls were shown to be well correlated. The MK and MWW tests on variance were applied to the squared residuals from a best fit line obtained from a locally weighted regression (loess) function in the manner suggested by Pegram (2000) and Villarini et al. (2011). Loess is a non-parametric regression technique that, unlike parametric curve fitting, does not make any assumptions about the functional form of the relationship between the dependent and independent variables. In addition to its simplicity, it is a well-recognised technique for curvefitting empirical data sets (Jacoby, 2000).

The impact on design estimates was evaluated by generating two sets of depth-frequency relationships of return periods varying from 5 to 100 -years. The first assumed stationarity and utilised the full available AM series. The second set of relationships were constructed using a truncated AM series subsequent to the observed shift in variance. To distinguish between climate change and natural climate variability, bootstrapped confidence intervals were constructed on the first set of depth frequency relationships to define the region of natural variability (Ntegeka and Willems, 2008).

\section{Study area and data}

Dublin, the capital city of Ireland, lies on the east coast of the country and receives an average annual rainfall of approximately $750 \mathrm{~mm}$. Annual rainfalls in this region are low and contrast sharply with totals elsewhere in the country, but particularly in elevated areas along the west coast where annual rainfalls of about $2800 \mathrm{~mm}$ are observed (Sweeney et al., 2006). Figure 1 and Table 1 show the details of the eight stations within the Dublin region that were analysed. Data from these stations was provided by Met Éireann, the Irish National Meteorological Service.

\section{Methodology}

Non-stationarity was investigated by carrying out robust nonparametric tests for monotonic and step change trends using the commonly applied and recognised tests of Mann-Kendal (Kendall, 1975) and Mann-Whitney-Wilcoxon (Wilcoxon, 1945) respectively.

Given that the study explores uncertainty in design estimates of rainfall, goodness-of-fit statistical testing was used to identify a valid distribution for modelling annual maximum daily rainfalls at the eight investigated stations. A goodness-of-fit test evaluates the degree of agreement between the empirical distribution of the tested data to that of an applied theoretical probability distribution. In this study, the Modified Anderson-Darling (MAD) goodness-of-fit test from Ahmad et al. (1988) was used to identify the suitability of a probability distribution. While the original test by Anderson and Darling (1952) afforded significant discriminating power to the extremes of the distribution, the modified test enhances this discriminating power by placing increased emphasis on the upper and lower distribution tails. Tails are regions of interest for hydrologists where extremes related to floods and droughts are typically located. For hydraulic engineers the upper tail is of particular interest in rainfall analysis, and represents events with high return periods.

To evaluate the impact of the observed non-stationarity in variance on rainfall design estimates, two sets of depthfrequency relationships at each station for return periods ranging from 5 to 100 -years were constructed. The first set was constructed with bootstrapped confidence intervals based on the full AM series assuming stationarity and the second was based on a partial AM series commencing in the year that followed the observed shift in variance. Confidence intervals acknowledge the various sources of uncer- 
Table 1. Details of rainfall stations in study area.

\begin{tabular}{llllll}
\hline $\begin{array}{l}\text { Station } \\
\text { No. }\end{array}$ & $\begin{array}{l}\text { Record Start } \\
\text { Year }\end{array}$ & $\begin{array}{l}\text { Record End } \\
\text { Year }\end{array}$ & $\begin{array}{l}\text { Altitude } \\
(\mathrm{m})\end{array}$ & Latitude & Longitude \\
\hline 332 & 1941 & 2006 & 64 & $53^{\circ} 34^{\prime} 8.40^{\prime \prime} \mathrm{N}$ & $6^{\circ} 8^{\prime} 31.20^{\prime \prime} \mathrm{W}$ \\
532 & 1942 & 2013 & 71 & $53^{\circ} 25^{\prime} 40.80^{\prime \prime} \mathrm{N}$ & $6^{\circ} 14^{\prime} 27.60^{\prime \prime} \mathrm{W}$ \\
1232 & 1962 & 2004 & 19 & $53^{\circ} 25^{\prime} 19.20^{\prime \prime} \mathrm{N}$ & $6^{\circ} 10^{\prime} 19.20^{\prime \prime} \mathrm{W}$ \\
1723 & 1941 & 2011 & 49 & $53^{\circ} 21^{\prime} 50.40^{\prime \prime} \mathrm{N}$ & $6^{\circ} 20^{\prime} 49.20^{\prime \prime} \mathrm{W}$ \\
1823 & 1941 & 2011 & 21 & $53^{\circ} 22^{\prime} 15.60^{\prime \prime} \mathrm{N}$ & $6^{\circ} 16^{\prime} 19.20^{\prime \prime} \mathrm{W}$ \\
1923 & 1941 & 2010 & 158 & $53^{\circ} 14^{\prime} 20.40^{\prime \prime} \mathrm{N}$ & $6^{\circ} 22^{\prime} 1.20^{\prime \prime} \mathrm{W}$ \\
4223 & 1950 & 2009 & 42 & $53^{\circ} 21^{\prime} 43.20^{\prime \prime} \mathrm{N}$ & $6^{\circ} 29^{\prime} 13.20^{\prime \prime} \mathrm{W}$ \\
7523 & 1973 & 2011 & 9 & $53^{\circ} 19^{\prime} 30.00^{\prime \prime} \mathrm{N}$ & $6^{\circ} 13^{\prime} 30.00^{\prime \prime} \mathrm{W}$ \\
\hline
\end{tabular}

Table 2. Year of significant step change in variance of annual extreme daily rainfall ("+" denotes a positive shift).

\begin{tabular}{ll}
\hline Station no. & Change Year \\
\hline 332 & $1984(+)$ \\
532 & $1984(+)$ \\
1232 & $1982(+)$ \\
1723 & $1985(+)$ \\
1823 & $1985(+)$ \\
1923 & $1984(+)$ \\
4223 & $1985(+)$ \\
7523 & $1985(+)$ \\
\hline
\end{tabular}

tainty in the estimation process of design quantiles (Khaliq et al., 2006) and in this case, define a region of natural climate variability. The methodology is considered a non-parametric approach and with advances in computational efficiency, is becoming increasingly popular for applications of this type (Prudhomme et al., 2003).

\section{Results}

No significant monotonic trends in the mean or variance of the annual daily maximum rainfalls in any of the eight analysed stations were detected by the MK test. The MWW step change analysis showed significant abrupt positive shifts in the means of annual daily extremes at only two of the eight stations, one occurring in 1961 and in the other in 1998 (stations no. 332 and 1723). This contrasted with the significantly more consistent change points that were observed in the variance of the AM series at the eight stations and in which the MWW test detected significant positive shifts between 1984 and 1985 at seven of the eight stations - the step change in station no. 1232 was observed in 1982 (Table 2).

The positive step changes in variance could be attributed to the increased frequency of extreme events that has been observed in more recent times (evident in Fig. 2b for Station no. 532, but representative of trends at the other stations). Note however, that this increased frequency of extreme rainfall events was not reflected in significant step changes in mean values of annual extremes from the investigated stations (Fig. 2a); again illustrating that non-stationarity can take different forms.

The MAD goodness-of-fit criterion identified the Generalised Extreme Value (GEV) distribution (Jenkinson, 1955) as being valid to model the annual maximum rainfall records at the eight stations.

This distribution is a flexible three parameter model that encompasses the type I - Gumbel, type II - Frechet and type III - Weibull, extreme value distributions. The cumulative distribution function (CDF) of a GEV distribution can be written as (Stedinger, 1993):

$$
\begin{aligned}
& F(x)=\exp \left\{-\left[1-k\left(\frac{x}{\alpha}-u\right)\right]^{1 / k}\right\} \quad k \neq 0 \\
& F(x)=\exp \left\{-\exp \left[-\left(\frac{x}{\alpha}-u\right)\right]\right\} \quad k=0
\end{aligned}
$$

where $\alpha$ is a scale parameter which can be estimated using the sample mean and $u$ is a dimensionless location parameter. The value of the shape parameter, $k$, determines the extreme value type I, II and III distribution. Specifically, the three cases $k=0, k<0$ and $k>0$ correspond to the Gumbel, Frechet, and Weibull distributions. The inverse relationships of Eqs. (1) and (2) respectively, are:

$$
\begin{aligned}
& x=\alpha\left\{u+\left[1-(-\ln F(x))^{k}\right] / k\right\} \quad k \neq 0 \\
& x=\alpha\{u-\ln [-\ln F(x)]\} \quad k=0
\end{aligned}
$$

Although the Method of Moments and the Maximum Likelihood Method are commonly used to determine distribution parameters, the Method of L-Moments (Khaliq et al., 2006) was used in this study. As detailed in Hosking (1990), LMoments offer advantages over other methods, one of which and of particular significance to this study, is that the method is less sensitive to extreme values (skewness) in the tails of the distribution.

Using the GEV distribution, depth frequency relationships for return periods ranging from 5 to 100 -years were constructed with full AM series (i.e. assuming the record is stationary) at the eight stations (Fig. 3). Bootstrapped confidence intervals are included in Fig. 3. In addition, Fig. 3 


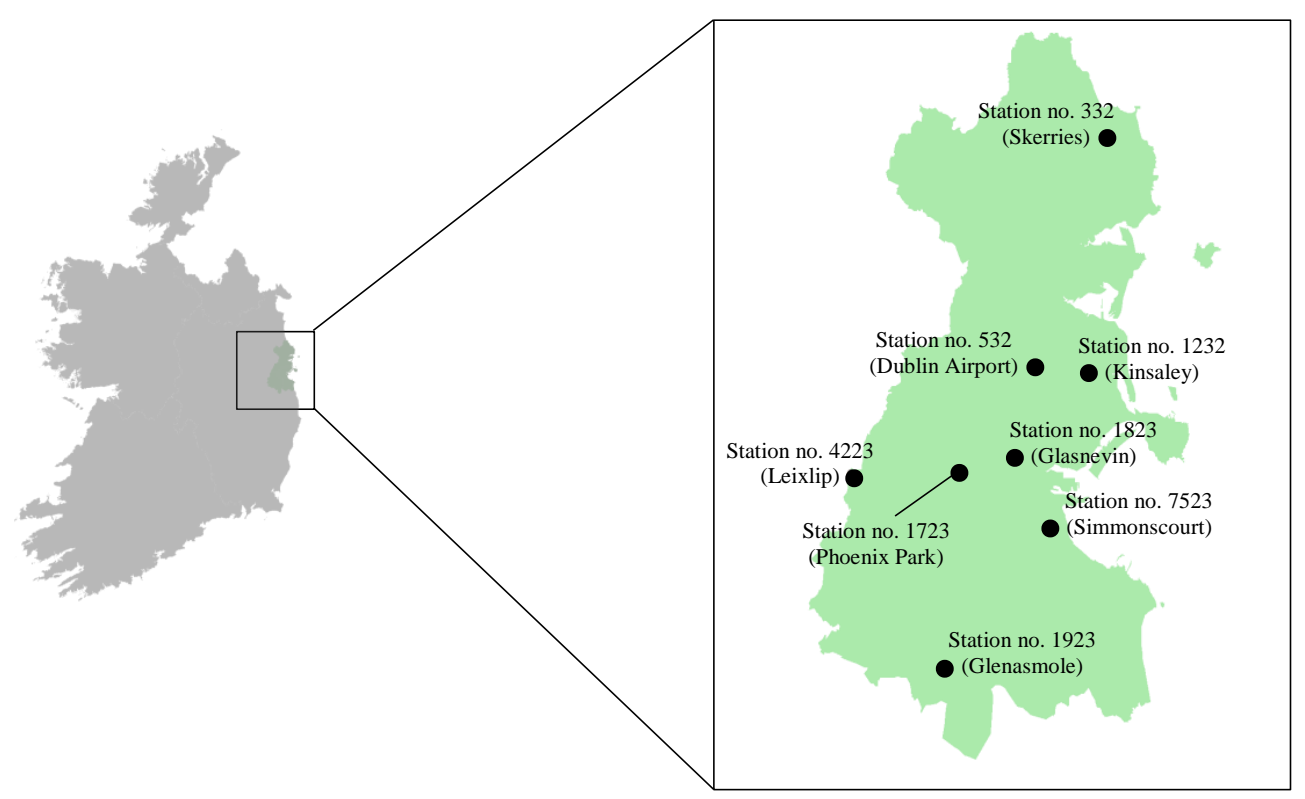

Figure 1. Names and locations of rainfall stations in study area.

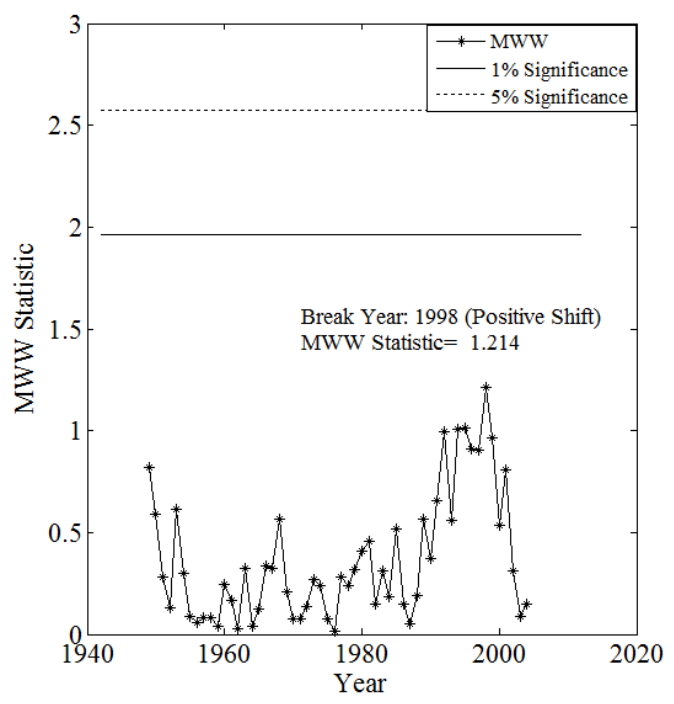

(a)

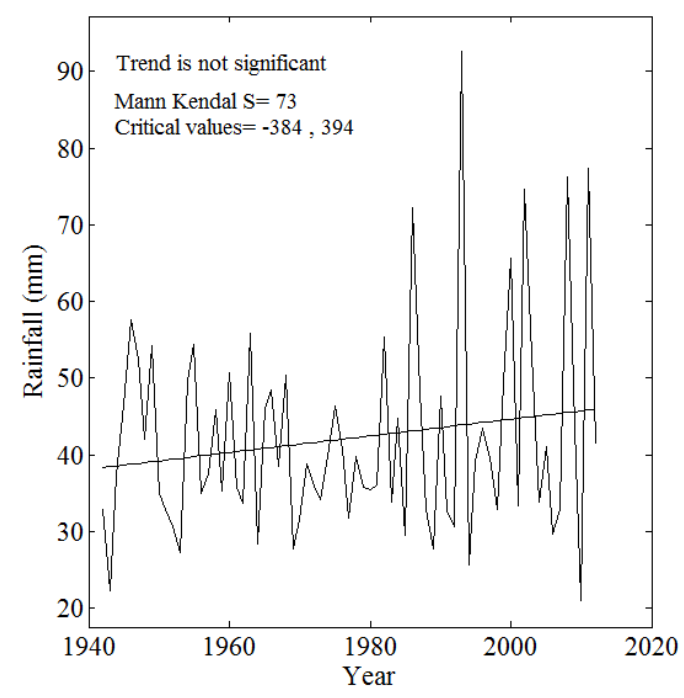

(b)

Figure 2. MWW (a) and MK (b) test results for mean annual maximum rainfall for Station no. 532.

includes depth frequency relationships derived using a truncated series subsequent to the observed step change in variance. The data highlights significant differences in design rainfall estimates in 7 out of the 8 stations that would be obtained from the two depth frequency relationships. The post step change estimates were generally higher, and in 6 stations were shown to fall outside the confidence intervals of the estimates from using the full record, suggesting a climate change signal. The data indicates that design daily rainfall estimates for the 5-year event using the post step-change depthfrequency relationship are between 5 and $16 \%$ higher than those determined using the full record and for the 100-year return period, are between 20 and $41 \%$ higher.

These results are potentially very significant for water resource managers and designers of water infrastructure. The results can be contextualised by considering, for example, the estimate of the 30-year quantile at station no. 532. An application of the MK and MWW statistical tests applied to the mean of the extreme daily rainfalls (Fig. 2) would indicate that an assumption of stationarity is valid and a rainfall depth of $74 \mathrm{~mm}$ with upper and lower confidence intervals corresponding to depths of 84 and $62 \mathrm{~mm}$ respectively 


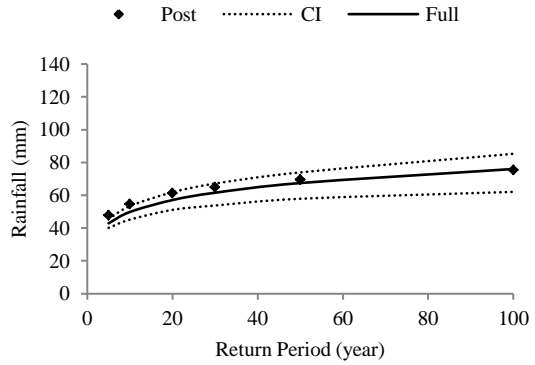

(a) Station no. 332

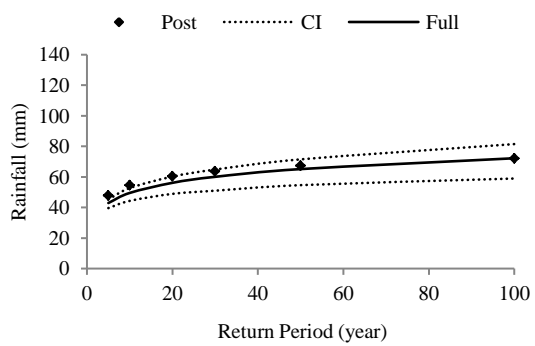

(c) Station no. 1232

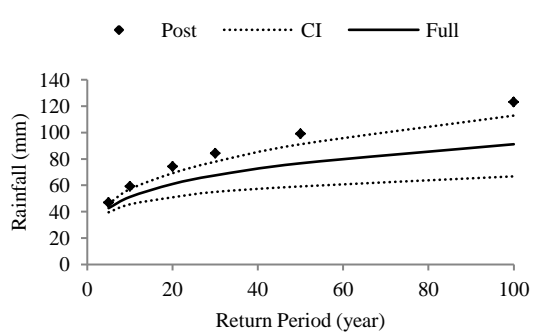

(e) Station no. 1823

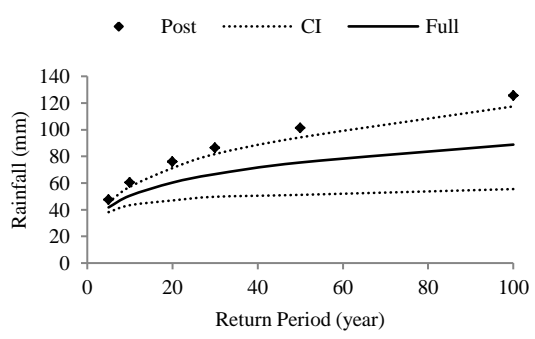

(g) Station no. 4223

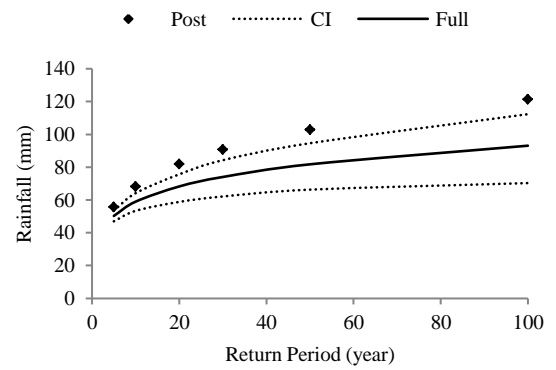

(b) Station no. 532

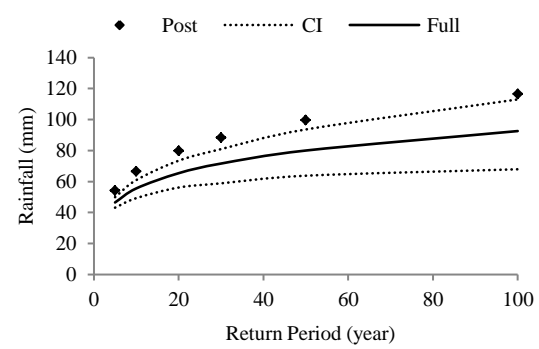

(d) Station no. 1723

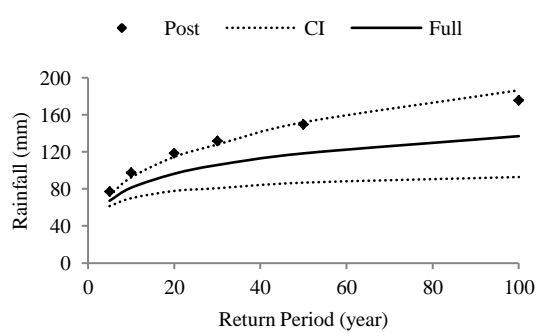

(f) Station no. 1923

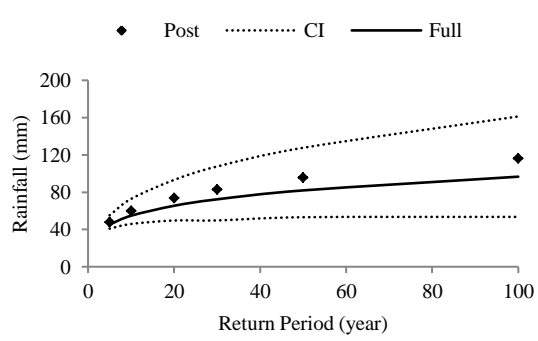

(h) Station no. 7523

Figure 3. Depth-frequency relationships using the full record (Full) with confidence intervals (CI) and for the post step-change data only (Post).

(Fig. 3b) would be determined. However, if variance (rather than mean) is the parameter adopted to identify the nonstationarity in the AM series, a significant step change in 1984 is detected (Fig. 4a) and determining the 30-year quantile with the truncated series, subsequent to the observed step change, yields a design estimate of $91 \mathrm{~mm}$ (Fig. 3b). The updated depth-frequency relationship in this regard, indicated that the $74 \mathrm{~mm}$ rainfall estimate would have a return period of just 14 years , almost doubling its frequency and highlighting the increased vulnerability of water infrastructures to under- design and increased failure risk should non-stationarity influences remain unidentified and ignored.

The non-stationarity in variance, reflected in a positive step change, across all eight stations in the study area, are shown to be statistically significant and their timing, being consistent with previously reported positive step changes in the winter index of the NAO in the early 1980's, is a strong indication that the change points reflect a climate change signal. 


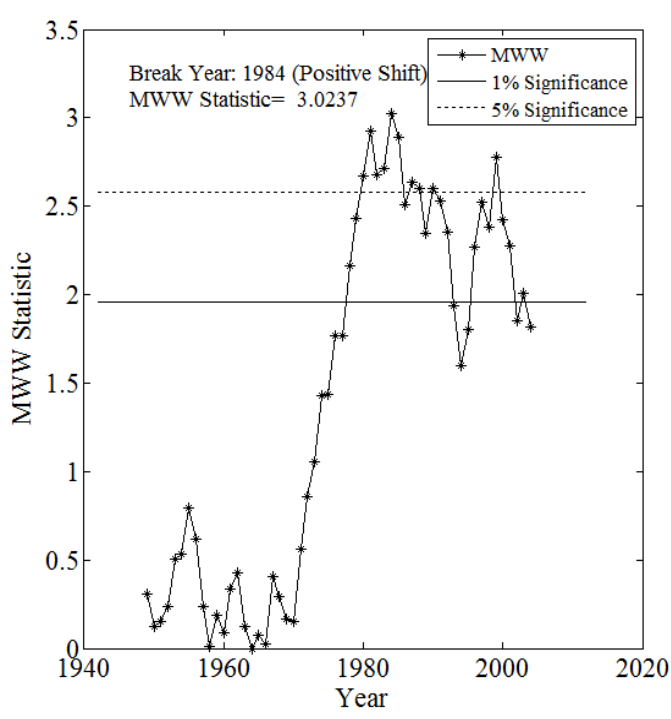

(a)

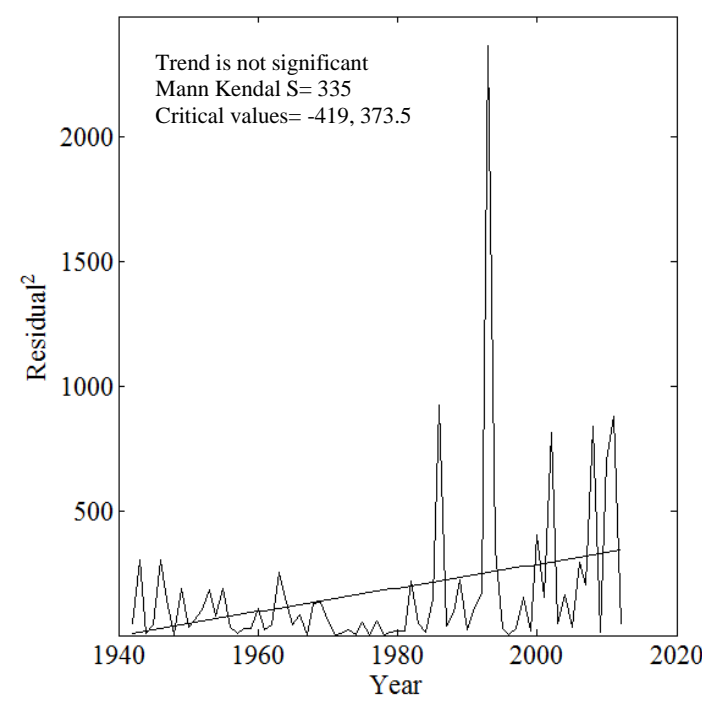

(b)

Figure 4. MWW (a) and MK (b) test results for variance of annual maximum rainfall for Station no. 532.

\section{Conclusions}

The stationarity (both gradual and in the form of abrupt step changes) in mean and variance of extreme annual daily rainfall of eight historical records in the Greater Dublin region was investigated in this paper and its impact on hydraulic design was evaluated. This also entailed distinguishing climate signals from natural climate variability in any observed non-stationarity. No significant linear trends were detected in the mean or variance of annual maximum daily rainfalls at the eight stations investigated. While positive step changes in the mean of these rainfalls were observed at two of the eight stations, significant positive step changes in variance were detected in all eight stations across the region. These exceeded the bounds of natural climate variability, suggesting that they result from a climate change signal. These change points were temporally consistent with a previously reported positive shift in the winter NAO since the beginning of the 1980's which highly influences rainfall patterns in Northern Europe. The impact on design estimates was shown to be significant, highlighting the importance of second order statistical testing (variance) in non-stationarity assessments of meteorological data records. The study highlights the differing effects that climate signals can have on the distribution of extreme rainfall depending on the geographical location and the importance of analysing the different forms non-stationarity may take. The results of the study reiterate the importance of updating design criteria in view of different forms of climate induced non-stationarity to reduce infrastructural risk and associated costs.
Acknowledgements. This work is part of the Earth and Natural Sciences Doctoral Studies Programme which is funded by the Higher Education Authority (HEA) in Ireland through the Programme for Research at Third Level Institutions, Cycle 5 (PRTLI5 ) and is co-funded by the European Regional Development Fund (ERDF).

\section{References}

Anderson, T. and Darling, D.: Asymptotic theory of certain“ goodness of fit" criteria based on stochastic processes, Ann. Math. Stat., 23, 193-212, 1952.

Arnell, N. W.: The effect of climate change on hydrological regimes in Europe: a continental perspective, Glob. Environ. Chang., 9, 5-23, 1999.

Burn, D. H. and Hag Elnur, M. a.: Detection of hydrologic trends and variability, J. Hydrol., 255, 107-122, 2002.

Chandler, R. E.: Analysis of rainfall variability using generalized linear models: A case study from the west of Ireland, Water Resour. Res., 38, 10-1, doi:10.1029/2001WR000906, 2002.

Coles, S.: An Introduction to Statistical Modeling of Extreme Values, Springer, 2001.

Dawadi, S. and Ahmad, S.: Changing climatic conditions in the Colorado River Basin: Implications for water resources management, J. Hydrol., 430/431, 127-141, 2012.

De Toffol, S., Laghari, A. N., and Rauch, W.: Are extreme rainfall intensities more frequent? Analysis of trends in rainfall patterns relevant to urban drainage systems., Water Sci. Technol., 59, 1769-76, 2009.

Hannachi, A.: Quantifying changes and their uncertainties in probability distribution of climate variables using robust statistics, Clim. Dyn., 27, 301-317, 2006.

Hoppe, H. and Kiely, G.: Precipitation over Ireland-Observed change since 1940, Phys. Chem. Earth, 24, 91-96, 1999. 
Hosking, J.: L-moments: analysis and estimation of distributions using linear combinations of order statistics, J. R. Stat. Soc., 52, 105-124, 1990.

Hurrell, J. W.: Decadal trends in the north atlantic oscillation: regional temperatures and precipitation., Science, 269, 676-679, 1995.

Hurrell, J. W. and Van Loon, H.: Decadal Variations In Climate Associated With The North Atlantic Oscillation, Clim. Change, 36, 301-326, 1997.

IPCC: Managing the Risks of Extreme Events and Disasters to Advance Climate Change Adaptation. A Special Report of Working Groups I and II of the Intergovernmental Panel on Climate Change, Cambridge and New York, UK and USA, 2012.

Jacoby, W.: Loess: a nonparametric, graphical tool for depicting relationships between variables, Elect. Stud., 19, 577-613, 2000.

Jenkinson, A. F.: The frequency distribution of the annual maximum (or minimum) values of meteorological elements, Q. J. R. Meteorol. Soc., 81, 158-171, 1955.

Jones, P., Jonsson, T., and Wheeler, D.: Extension to the North Atlantic Oscillation using early instrumental pressure observations from Gibraltar and south-west Iceland, Int. J. Climatol., 17, 1433-1450, 1997.

Jung, I.-W., Bae, D.-H., and Kim, G.: Recent trends of mean and extreme precipitation in Korea, Int. J. Climatol., 31, 359-370, 2011.

Kendall, M.: Rank Correlation Methods: M Kendall, 4th Edn., Charles Griffin, London, 1975.

Khaliq, M. N., Ouarda, T. B. M. J., Ondo, J.-C., Gachon, P., and Bobée, B.: Frequency analysis of a sequence of dependent and/or non-stationary hydro-meteorological observations: A review, J. Hydrol., 329, 534-552, 2006.

Kiely, G.: Climate change in Ireland from precipitation and streamflow observations, Adv. Water Resour., 23, 141-151, 1999.

Klein Tank, A., Zwiers, F. W., and Zhang, X.: Guidelines on Analysis of extremes in a changing climate in support of informed decisions for adaptation, World Meteorological Organization, 2009.

Kundzewicz, Z. W. and Robson, A. J.: Detecting Trend And Other Changes In Hydrological Data, WMCDMP - 45, 175 pp., 2000.

Leahy, P. G. and Kiely, G.: Short Duration Rainfall Extremes in Ireland: Influence of Climatic Variability, Water Resour. Manag., $25,987-1003,2010$.

López, J. and Francés, F.: Non-stationary flood frequency analysis in continental Spanish rivers, using climate and reservoir indices as external covariates, Hydrol. Earth Syst. Sci., 17, 3189-3203, doi:10.5194/hess-17-3189-2013, 2013.
Ntegeka, V. and Willems, P.: Trends and multidecadal oscillations in rainfall extremes, based on a more than 100-year time series of 10 min rainfall intensities at Uccle, Belgium, Water Resour. Res., 44, doi:10.1029/2007WR006471, 2008.

Osborn, T. and Hulme, M.: Observed trends in the daily intensity of United Kingdom precipitation, Int. J. Climatol., 364, 347-364, 2000.

Pegram, G.: Testing for Change in Variability and Persistence in Time Series, in Detecting Trend And Other Changes In Hydrological Data, WMCDMP - 45, World Meteorological Organization - Geneva, 2000.

Prudhomme, C., Jakob, D., and Svensson, C.: Uncertainty and climate change impact on the flood regime of small UK catchments, J. Hydrol., 277, 1-23, 2003.

Robson, A. J., Jones, T. K., Reed, D. W., and Bayliss, A. C.: A Study oF National Trend and Variation in UK Floods, Int. J. Climatol., 18, 165-182, 1998.

Rodwell, M. J., Rowell, D. P., and Folland, C. K.: Oceanic forcing of the wintertime North Atlantic Oscillation and European climate, Nature, 398, 320-323, 1999.

Sen Roy, S. and Balling, R. C.: Trends in extreme daily precipitation indices in India, Int. J. Climatol., 24, 457-466, 2004.

Sheridan, T.: Analysis of trends at some Irish rainfall stations, Dublin, Ireland, 2001.

Stedinger, J.: Frequency analysis of extreme events, Handb. Hydrol., 18, 1-66, 1993.

Sweeney, J.: Regional weather and climates of the British Isles-Part 6: Ireland, Weather, 66, 20-27, 2014.

Sweeney, J., Donnelly, A., McElwain, L., and Jones, M.: Climate Change Indicators For Ireland, Environmental Protection Agency, Ireland, 2006.

Trigo, R. M., Pozo-Vázquez, D., Osborn, T. J., Castro-Díez, Y., Gámiz-Fortis, S., and Esteban-Parra, M. J.: North Atlantic oscillation influence on precipitation, river flow and water resources in the Iberian Peninsula, Int. J. Climatol., 24, 925-944, 2004.

Villarini, G., Smith, J. A., Ntelekos, A. A., and Schwarz, U.: Annual maximum and peaks-over-threshold analyses of daily rainfall accumulations for Austria, J. Geophys. Res., 116, D05103, doi:10.1029/2010JD015038, 2011.

Visbeck, M. and Hurrell, J.: The North Atlantic Oscillation: past, present, and future, Proc. Natl. Acad. Sci. USA, 98, 1287612877, 2001.

Wilcoxon, F.: Individual comparisons by ranking methods, Biometrics Bull., 1, 80-83, 1945. 